\title{
Selective inhibition of 12-lipoxygenase protects islets and beta cells from inflammatory cytokine-mediated beta cell dysfunction
}

\author{
David A. Taylor-Fishwick • Jessica Weaver • Lindsey Glenn • Norine Kuhn • \\ Ganesha Rai • Ajit Jadhav • Anton Simeonov • Angela Dudda • Dieter Schmoll • \\ Theodore R. Holman • David J. Maloney • Jerry L. Nadler
}

Received: 14 July 2014 / Accepted: 23 October 2014 / Published online: 23 November 2014

(C) Springer-Verlag Berlin Heidelberg 2014

\begin{abstract}
Aims/hypothesis Islet inflammation leads to loss of functional pancreatic beta cell mass. Increasing evidence suggests that activation of 12-lipoxygenase leads to inflammatory beta cell loss. This study evaluates new specific small-molecule inhibitors of 12-lipoxygenase for protecting rodent and human beta cells from inflammatory damage.

Methods Mouse beta cell lines and mouse and human islets were treated with inflammatory cytokines IL-1 $\beta, \mathrm{TNF} \alpha$ and IFN $\gamma$ in the absence or presence of novel selective 12lipoxygenase inhibitors. Glucose-stimulated insulin secretion
\end{abstract}

Electronic supplementary material The online version of this article (doi:10.1007/s00125-014-3452-0) contains peer-reviewed but unedited supplementary material, which is available to authorised users.

D. A. Taylor-Fishwick $(\bowtie) \cdot$ J. Weaver

Department of Microbiology and Molecular Cell Biology, Eastern

Virginia Medical School, 700 W. Olney Road,

Norfolk, VA 23507, USA

e-mail: TaylorD@evms.edu

D. A. Taylor-Fishwick $\cdot$ L. Glenn $\cdot$ N. Kuhn $\cdot$ J. L. Nadler

Department of Internal Medicine, Eastern Virginia Medical School,

Norfolk, VA, USA

D. A. Taylor-Fishwick · J. L. Nadler

Strelitz Diabetes Center, Eastern Virginia Medical School,

Norfolk, VA, USA

G. Rai $\cdot$ A. Jadhav $\cdot$ A. Simeonov $\cdot$ D. J. Maloney

NIH Chemical Genomics Center, National Center for Advancing

Translational Sciences, NIH, Rockville, MD, USA

A. Dudda

DSAR Drug Disposition, Sanofi, Frankfurt, Germany

D. Schmoll

Diabetes Division, R\&D, Sanofi, Frankfurt, Germany

T. R. Holman

Department of Biochemistry, UCSC, Santa Cruz, CA, USA
(GSIS), gene expression, cell survival and 12-Shydroxyeicosatetraenoic acid (12-S-HETE) levels were evaluated using established methods. Pharmacokinetic analysis was performed with the lead inhibitor in CD1 mice.

Results Inflammatory cytokines led to the loss of human beta cell function, elevated cell death, increased inflammatory gene expression and upregulation of 12-lipoxygenase expression and activity (measured by 12-S-HETE generation). Two 12lipoxygenase inhibitors, Compounds 5 and 9, produced a concentration-dependent reduction of stimulated 12-S-HETE levels. GSIS was preserved in the presence of the 12lipoxygenase inhibitors. 12-Lipoxygenase inhibition preserved survival of primary mouse and human islets. When administered orally, Compound 5 reduced plasma 12-S-HETE in $\mathrm{CD} 1$ mice. Compounds 5 and 9 preserved the function and survival of human donor islets exposed to inflammatory cytokines.

Conclusions/interpretation Selective inhibition of 12lipoxygenase activity confers protection to beta cells during exposure to inflammatory cytokines. These concept validation studies identify 12-lipoxygenase as a promising target in the prevention of loss of functional beta cells in diabetes.

Keywords 12-Lipoxygenase $\cdot$ Cytokines $\cdot$ Diabetes $\cdot$ Drug discovery $\cdot$ Inhibitors $\cdot$ Islets

$\begin{array}{ll}\text { Abbreviations } & \\ \text { 12-S-HETE } & \text { 12-S-hydroxyeicosatetraenoic acid } \\ \text { 12-S-HPETE } & \text { 12-S-hydroperoxieicosatetraenoic acid } \\ \text { AA } & \text { Arachidonic acid } \\ \text { COX } & \text { Cyclooxygenase } \\ \text { ER } & \text { Endoplasmic reticulum } \\ \text { GAPDH } & \text { Glyceraldehyde-3-phosphate dehydrogenase } \\ \text { GSIS } & \text { Glucose-stimulated insulin secretion } \\ \text { HQ } & \text { Hydroquinoline } \\ \text { IONO } & \text { Calcium ionophore }\end{array}$


MCP1 Monocyte chemoattractant protein-1

RFU Relative fluorescence units

\section{Introduction}

Islet inflammation is a key contributor to loss of functional pancreatic beta cell mass in both type 1 and type 2 diabetes [1-3]. Studies have implicated inflammatory cytokines and immune cell infiltration leading to pathways, including oxidative and endoplasmic reticulum (ER) stress activation, that damage beta cell viability [4-11]. Despite advances, key therapeutic targets leading to new drug-based strategies to prevent the loss of functional beta cell mass have not been clearly identified [12]. There is accumulating evidence that activation of 12-lipoxygenase is a key link between cytokinemediated inflammation and beta cell damage [13]. 12Lipoxygenase is an oxygenase for arachidonic acid (AA) and other fatty acids, leading to proinflammatory lipids including 12-S-hydroperoxieicosatetraenoic acid (12-SHPETE) and 12-S-hydroxyeicosatetraenoic acid (12-SHETE) [14, 15]. 12-Lipoxygenase is expressed in rodent and human islets $[11,15-18]$ and is upregulated under conditions of metabolic and cytokine stress. Direct addition of 12-SHETE can impair beta cell function or can lead to loss of human beta cell viability [13, 15, 16, 19-22]. Recent evidence indicates that increased expression of 12-lipoxygenase in islets is a common feature of both rodent and human models of type 1 and type 2 diabetes [11, 13, 15, 17, 22]. Deletion of 12lipoxygenase protects mice against hyperglycaemia induced with low dose streptozotocin. In the NOD mouse, 12lipoxygenase deletion confers a near complete protection against type 1 diabetes and also reduces immune cell activation [17, 23]. Interestingly, two independent groups have shown that 12-lipoxygenase activation also participates in high-fat-induced insulin resistance and adipose tissue inflammation [24, 25]. Deletion of 12-lipoxygenase significantly inhibits the development of insulin resistance in mice fed a high-fat diet. Products of 12-lipoxygenase lead to ER stress, oxidative stress and generation of proinflammatory cytokines $[11,13,14,26]$. Very recent evidence has shown that 12 lipoxygenase can generate IL-12 production in the islet [23, 27]. Local IL-12 production may propagate an immune inflammatory state that further induces beta cell damage [27]. In human islets obtained from donors with type 2 diabetes, 12lipoxygenase is upregulated and is associated with early islet dysfunction and increased migration of $\mathrm{CD} 45^{+}$leucocytes [11]. Studies to date have not shown any adverse effects associated with a targeted genetic deletion of 12 lipoxygenase in rodent models. Thus, pharmacological inhibition of 12-lipoxygenase could be a promising target by which to prevent or even help stop the loss of functional beta cell mass in diabetes. Historically, this field of research has been limited by the lack of selective 12-lipoxygenase inhibitors. We previously reported the discovery, synthesis and optimisation of inhibitors that are highly selective for 12lipoxygenase [28]. The current proof-of-concept study demonstrates the efficacy of these small-molecule inhibitors of 12lipoxygenase in protecting rodent and human beta cells from damage associated with inflammation.

\section{Methods}

Ethics Protocols and procedures were reviewed and approved by relevant institutional regulatory committees.

Mouse islets, human islets and cell culture Mouse islets were freshly isolated from 6-week-old male C57BL/6J (Jackson Laboratory, Bar Harbor, ME, USA) by common-bile-duct cannulation and collagenase digestion as previously reported [29]. Islets were hand picked prior to use. Human islets were obtained from Integrated Islet Distribution Project (http://iidp. coh.org) and cultured in CMRL media (Mediatech, Manassas, VA, USA). MIN6, $\beta$ TC-3 and INS- 1 beta cells were cultured in standard media as previously reported [30]. Media and supplements were obtained from (Life Technologies, Grand Island, NY, USA). Cells were cultured at $37^{\circ} \mathrm{C}$ in a $5 \% \mathrm{CO}_{2} /$ humidified atmosphere.

Treatment and real-time PCR Cells or islets were treated with species-specific triple-cytokine cocktail (IL-1 $\beta 5 \mathrm{ng} / \mathrm{ml}$, $\mathrm{TNF} \propto 10 \mathrm{ng} / \mathrm{ml}$ and IFN $\gamma 100 \mathrm{ng} / \mathrm{ml}$; R\&D Systems, Minneapolis, MN, USA) with or without inhibitor. Compounds 5 or 9 were added $30 \mathrm{~min}$ before stimuli and retained for the remainder of the experiment. cDNA was prepared from isolated RNA as previously reported [13, 27, 31]. Speciesspecific Taqman primers were used for $A L O X 12, I L-12 p 40$ (also known as $I L 12 B), I F N \gamma$ (IFNG), monocyte chemoattractant protein-1 ( $M C P 1)$, actin and glyceraldehyde3-phosphate dehydrogenase (GAPDH) (Life Technologies). Real-time PCR reactions were performed in triplicate on a CFX96 Thermal Cycler (Bio-Rad, Hercules, CA, USA). The housekeeping genes actin and GAPDH were used to normalise the data. The $2^{-\Delta \Delta \mathrm{C}_{\mathrm{t}}}$ method was used to analyse the data.

Glucose-stimulated insulin secretion For determination of glucose-stimulated insulin secretion (GSIS), cells or islets were stimulated for $4 \mathrm{~h}$ with light-protected 12-S-HETE in ethanol or triple-cytokine cocktail as described for real-time PCR. Compounds 5 or 9 were added 30 min before application of stimuli and retained for the remainder of the experiment. Each condition had 40 islets or, for cell lines, an $80 \%$ confluent well (6-well plate). After stimulation islets/cells were incubated in low-glucose KRB for $1 \mathrm{~h}$ at $37^{\circ} \mathrm{C}$. For 
GSIS, insulin, following $30 \mathrm{~min}$ incubation in $3 \mathrm{mmol} / 1$ glucose-KRB (low-glucose) or $16.7 \mathrm{mmol} / 1$ glucose-KRB (high-glucose), was measured by ELISA (Mercodia, Winston Salem, NC, USA) as previously reported [27].

12-S-HETE ELISA Before treatment, cells and islets were incubated in media without serum for $1 \mathrm{~h}$. Serum-free media was replaced by media containing $1 \%$ BSA. Cells were treated with $100 \mu \mathrm{mol} / \mathrm{l}$ AA (ENZO Life Sciences, Farmingdale, NY, USA) and $5 \mu \mathrm{mol} / 1$ A23187 (Sigma, St. Louis, MO, USA) for $4 \mathrm{~h}$ at $37^{\circ} \mathrm{C}$ without or with inhibitor. Compounds 5 or 9 were added $30 \mathrm{~min}$ before application of stimuli and retained for the remainder of the experiment. 12-S-HETE was measured in extracted samples. The methodology for extraction and ELISA followed the manufacturer's instructions (ENZO Life Sciences).

Apoptosis detection Apoptosis was detected by using a caspase-3 assay and fluorescence microscopy. For the caspase-3 assay, pro-caspase-3 cleavage was measured in treated cells or islets using a Caspase-3 Assay kit (BD Pharmingen, Franklin Lakes, NJ, USA) following the manufacturer's instructions. Results were normalised to islet number. Fluorescence was measured (excitation wavelength $380 \mathrm{~nm}$, emission wavelength 440/460 nm) using a SpectraMax Microplate Reader (Molecular Devices, Sunnyvale, CA, USA).

For fluorescence microscopy, treated islets (up to 200 per condition) were washed with cold PBS and incubated for $30 \mathrm{~min}$ at $4^{\circ} \mathrm{C}$ in PBS containing $0.1 \mu \mathrm{mol} / 1$ YO-PRO- 1 and $1 \mu \mathrm{g} / \mathrm{ml}$ propidium iodide (Life Technologies). Fluorescence was quantified as previously reported $[13,27]$. Briefly, after islets were washed in cold PBS, green/red/bright field images were captured with an Axiophot microscope (Zeiss, Jena, Germany) and green fluorescent intensity was quantified using Axiovision image analysis software (Zeiss). A minimum of five random fields from each of three separate experiments was analysed. All islets $\left(>1,000 \mu \mathrm{m}^{2}\right)$ were analysed in each field. The densitometric fluorescence value for YOPRO-1, as a ratio of islet area, was normalised to background. Data is expressed either as relative fluorescent units (RFU) or as an apoptotic index (the relative normalised expression with stimuli [positive control] signal being defined as unity).

Oral pharmacokinetics Pharmacokinetic variables were evaluated following a single oral bolus administration of $50 \mathrm{mg} / \mathrm{kg}$ Compound 5 as wet-milled suspension in HEC/Tween $(99.5 \%$ HEC $(0.5 \% / 0.5 \%$ Tween 80$)$ to male CD1 mice (Harlan Winkelmann, Paderborn, Germany). Plasma samples taken at each time point $(n=3)$ were analysed using Sciex $4000 \mathrm{LC} /$ MS/MS (AB SCIEX, Framingham, MA, USA). Pharmacokinetic variables were calculated using WinNonlin V 5.2.1 (Pharsight Corporation, Mountain View, CA, USA). Plasma
12-S-HETE was detected in extracted samples by ELISA according to the manufacturer's instructions (ENZO Life Sciences).

Statistical analysis Experiments were performed in triplicate (separate experiments) at a minimum. Student's $t$ test (twotailed) or one-way ANOVA with Tukey's post hoc testing (Prism 4.0; GraphPad Software, La Jolla, CA, USA) were used to determine statistical significance (95\% CI and $p<0.05)$. Data shown are mean \pm SEM.

\section{Results}

12-S-HETE is a mediator of proinflammatory cytokineinduced beta cell dysfunction Exposure of human donor islets to a cocktail of three inflammatory cytokines (IFN $\gamma$, IL-1 $\beta$, $\mathrm{TNF} \alpha$ ) resulted in loss of beta cell function, elevated gene expression and an increase in cell death. Concomitant with induced islet dysfunction, treatment of human donor islets with the cytokine cocktail resulted in elevated gene expression for $A L O X 12$, the transcript of 12-lipoxygenase. Five separate donor preparations of human islets were assayed for $A L O X 12$ expression (D1-D5, Fig. 1a). Relative to untreated control an overall significant 5.94 \pm 1.2-fold increase in 12-lipoxygenase expression occurred following cytokine stimulation $(p<0.01)$.

One product of 12-lipoxygenase enzyme activity is the bioactive lipid metabolite 12-S-HETE. To determine whether the eicosanoid 12-S-HETE contributes to islet dysfunction, human donor islets were stimulated directly with 12-S-HETE. In control (vehicle-treated) human donor islets exposure to $16.7 \mathrm{mmol} / 1$ glucose resulted in a significant increase in insulin secretion; this response was significantly attenuated in human donor islets following a $4 \mathrm{~h}$ incubation with $1 \mathrm{nmol} / \mathrm{l}$ or $100 \mathrm{nmol} / 1$ 12-S-HETE (Fig. 1b). Cell death was measured microscopically (representative images and quantification shown in Fig. 1c-e) $(p<0.0001)$ and was elevated in human donor islets exposed to $100 \mathrm{nmol} / 1$ 12-S-HETE overnight, relative to control (vehicle-treated) islets.

To establish whether cytokines induce 12-S-HETE, human donor islets were treated with cytokines and a dilution series of AA, a substrate for 12-lipoxygenase. After a $4 \mathrm{~h}$ stimulation, 12-S-HETE levels in the culture media was measured by ELISA. An elevation of 12-S-HETE in the culture media was not detectable after incubation with cytokines alone. Addition of AA resulted in a concentration-dependent increase in media 12-S-HETE. Detectable 12-S-HETE in the media was significantly elevated when cytokine stimulation was combined with AA, relative to AA alone ( $p<0.01$, Fig. 1f).

These data suggest that activation of 12-lipoxygenase in human donor islets results from cytokine stimulation. The bioactive lipid, 12-S-HETE, is a potential mediator of cytokine-induced islet dysfunction. 

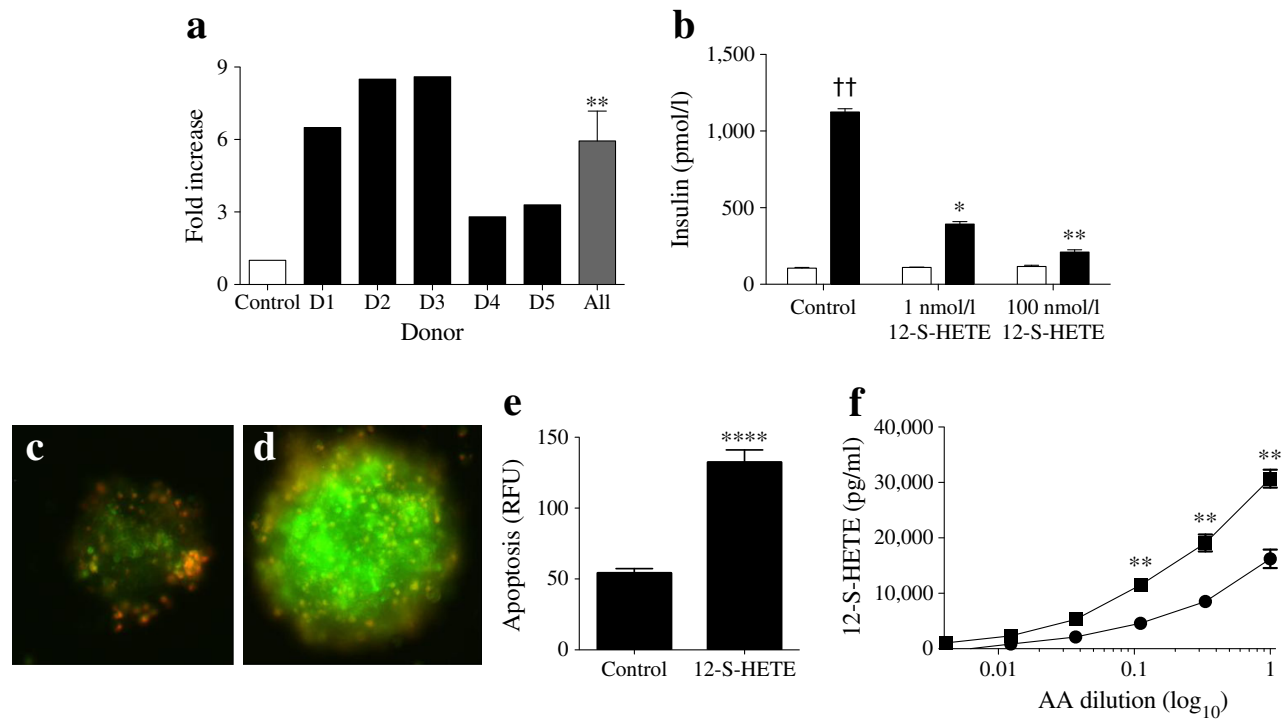

Fig. 1 12-S-HETE is a candidate mediator of inflammatory cytokineinduced human islet dysfunction. (a) Expression of $A L O X 12$ in five distinct human donor islet preparations (D1-D5) and combined islet preparations (All) following stimulation with cytokines (IFN $\gamma$, IL-1 $\beta$, $\mathrm{TNF} \alpha$ ). Fold increase in $A L O X 12$ expression relative to unstimulated (control) islets is shown. (b) GSIS in human islets treated with 12-SHETE. Insulin secretion was measured in $3 \mathrm{mmol} / \mathrm{l}$ (white bars) and $16.7 \mathrm{mmol} / 1$ (black bars) glucose. (c-e) Cell death in human islets treated

8-Hydroquinolines inhibit 12-lipoxygenase activity in mouse beta cell lines A high-throughput screening campaign identified an 8-hydroquinoline (8-HQ)-based chemical series that demonstrated nanomolar potency for inhibition of 12lipoxygenase [28]. The compounds were found to be selective, having no significant activity against 5- or 15-lipoxygenases or cyclooxygenase (COX) enzymes (electronic supplementary material [ESM] Table 1). Compounds 5 and 9 (structures shown in ESM Fig. 1) showed a robust and selective inhibition of 12-lipoxygenase in cell-free assays. The ability of these compounds to inhibit 12-lipoxygenase in beta cell lines was measured. Homogeneous mouse beta cell lines were stimulated with AA and calcium ionophore (IONO) to elevate 12lipoxygenase activity. The resultant production of 12-S-HETE was measured in the absence or presence of Compounds 5 or 9 . Treatment with AA/IONO for $4 \mathrm{~h}$ resulted in a significant elevation of 12-S-HETE detected in the culture media: 12-SHETE levels rose to $7,548 \pm 864 \mathrm{pg} / \mathrm{ml}$ in AA/IONO-treated MIN6 cells relative to basal levels of $531 \pm 63 \mathrm{pg} / \mathrm{ml}$ in unstimulated MIN6 cells $(p<0.01)$. Inclusion of Compound 9 and Compound 5 resulted in a concentration-dependent inhibition of AA/IONO-stimulated 12-S-HETE detected in media from MIN6, with a calculated $\mathrm{IC}_{50}$ value of $0.78 \mu \mathrm{mol} / 1$ and $0.59 \mu \mathrm{mol} / \mathrm{l}$, respectively (Fig. 2a). A similar effect was observed in $\beta$ TC-3 cells (Fig. 2b). Suppression of the AA/IONOstimulated 12-S-HETE increase by these compounds was also observed in the rat beta cell line INS-1 (ESM Fig. 2). with $100 \mathrm{nmol} / 1$ 12-S-HETE. Quantified apoptosis, determined by YOPRO-1 staining is shown graphically (e), with representative images for control (c) and 12-S-HETE-treated islets (d). (f) 12-S-HETE production in human islets stimulated with AA in the absence (circles) or presence (squares) of cytokines. All experiments were performed across a minimum of three donors. ${ }^{*} p<0.05,{ }^{* *} p<0.01, * * * * p<0.0001$ vs control (a, e) or AA alone (f); (b) ${ }^{\dagger} p<0.01$ vs control $3 \mathrm{mmol} / 1$ glucose, ${ }^{*} p<0.05,{ }^{* *} p<0.01$ vs control $16 \mathrm{mmol} / \mathrm{l}$ glucose

Structural analogues that exhibited low potency in the 12lipoxygenase biochemical assay did not significantly inhibit 12-S-HETE (Fig. 2c). Compound F has an 8-HQ scaffold and a low 12-lipoxygenase inhibitory potency $\left(\mathrm{IC}_{50}>70 \mu \mathrm{mol} / \mathrm{l}\right.$; ESM Fig. 1). Unlike Compound 9, no significant inhibition of AA/IONO-induced 12-S-HETE in $\beta$ TC-3 cells was observed with Compound $\mathrm{F}$ at concentrations up to $15 \mu \mathrm{mol} / \mathrm{l}$. 12-SHETE in $\beta$ TC-3 cells was significantly elevated when cytokine stimulation was combined with AA, relative to AA alone $(p<0.01$, Fig. $2 d)$.

These data show that Compounds 9 and 5 selectively inhibit 12-lipoxygenase in whole cells, as measured by inhibition of 12-S-HETE production in murine beta cell lines.

Inhibition of 12-lipoxygenase preserves function of beta cell lines exposed to proinflammatory cytokines To assess beta cell function, measurement of GSIS in a static model was performed. Insulin secretion following transition from $3 \mathrm{mmol} / 1$ glucose media (low-glucose) to $16.7 \mathrm{mmol} / 1$ glucose media (high-glucose) was significantly increased in the mouse beta cell lines MIN6 and $\beta$ TC-3 (Control, Fig. 3a, b; $p<0.05)$. After a $4 \mathrm{~h}$ exposure to the triple-cytokine cocktail the GSIS response was absent $(p=\mathrm{NS})$. The GSIS response in cytokine-treated cells was preserved by addition of $10 \mu \mathrm{mol} / 1$ Compound 5 or Compound 9 $(p<0.05)$. Compounds alone did not affect the GSIS response (ESM Fig. 3a, b). 
Fig. 2 Inhibition of 12lipoxygenase activity in beta cell lines. (a) Inhibition of AA/IONO (AA/I)-stimulated 12-S-HETE in MIN6 cells by Compounds 5 (squares) and 9 (circles); a similar effect was seen in $\beta \mathrm{TC}-3$ cells (b). (c) AA/I-stimulated 12-SHETE in $\beta$ TC- 3 cells in the presence of Compound 9 and inactive Compound F. (d) 12-SHETE production in $\beta$ TC-3 cells stimulated with AA in the absence (triangles) or presence (diamonds) of cytokines. [Cpd], concentration of compound. ${ }^{*} p<0.05 ; * * p<0.01$ vs AA/I $(\mathbf{a}-\mathbf{c})$ or AA alone (d), $n=3$ a

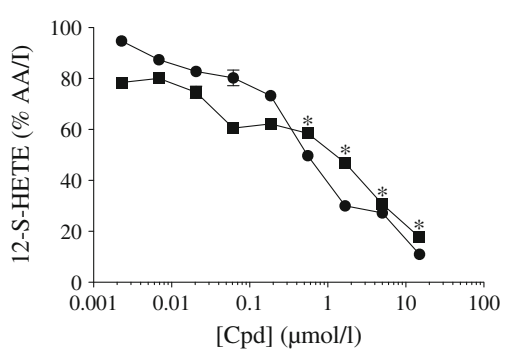

c

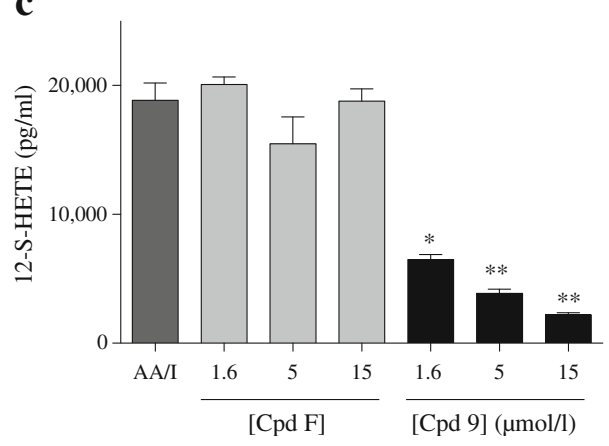

b

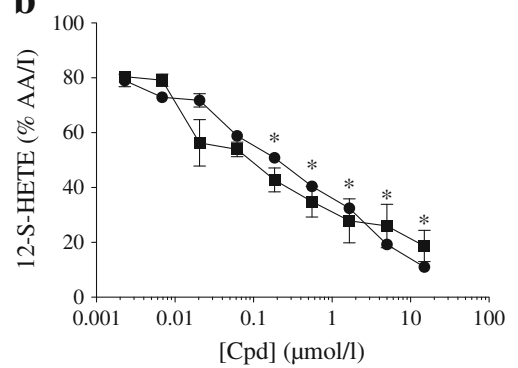

d

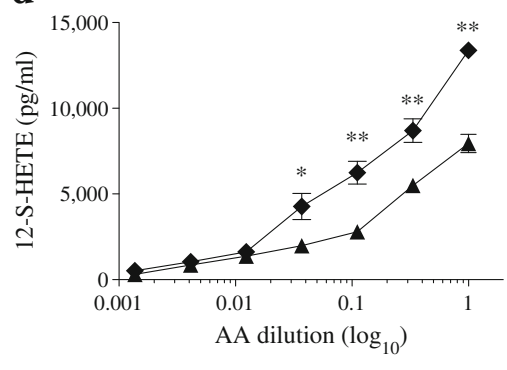

These data indicate that inhibition of 12-lipoxygenase in beta cell lines can preserve beta cell function during exposure to inflammatory cytokines. Impairment of the GSIS response in beta cells, resulting from exposure to cytokines, can be blocked by compound inhibitors of 12-lipoxygenase.

\section{Inhibition of 12-lipoxygenase preserves survival of primary} mouse islets exposed to proinflammatory cytokines Increased cell death is an outcome of longer exposure of islets and beta cells to proinflammatory cytokines. To determine whether activation of 12-lipoxygenase is an effector of this pathway, primary islets from mice were studied. Islets were incubated with the triple-cytokine mixture overnight in the absence and presence of Compound 5 or 9 . Apoptosis was determined by measuring caspase-3 activity (Fig. $4 \mathrm{a}$ ) and also microscopically, through quantification of YO-PRO-1/propidium iodide fluorescent stains (Fig. 4b). Cytokine-induced caspase-3

$\mathbf{a}$

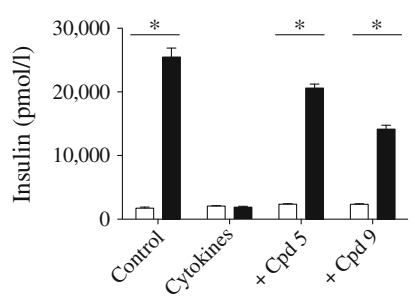

b

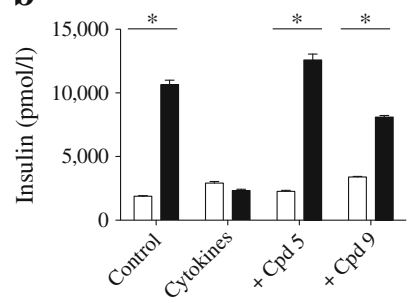

Fig. 3 Preserved GSIS in mouse beta cell lines exposed to cytokines. Insulin secretion in MIN6 (a) or $\beta$ TC-3 (b) cells in response to $3 \mathrm{mmol} / 1$ (white bars) and $16.7 \mathrm{mmol} / \mathrm{l}$ (black bars) glucose in untreated (Control) and cytokine-stimulated cells in the absence or presence of $10 \mu \mathrm{mol} / 1$ Compound (Cpd) 5 or $9 .{ }^{*} p<0.05$ for the indicated comparisons, $n=4$ activity or cell death was blocked by co-incubation with the 12-lipoxygenase inhibitors. Cytokine-induced cell death in the homogeneous beta cell line, $\beta$ TC-3 was prevented by 12 lipoxygenase inhibitors (ESM Fig. 4). As a separate marker of cytokine-induced changes in mouse islets, induction of the genes $M c p 1$ and $I l-12 p 40$ was examined.
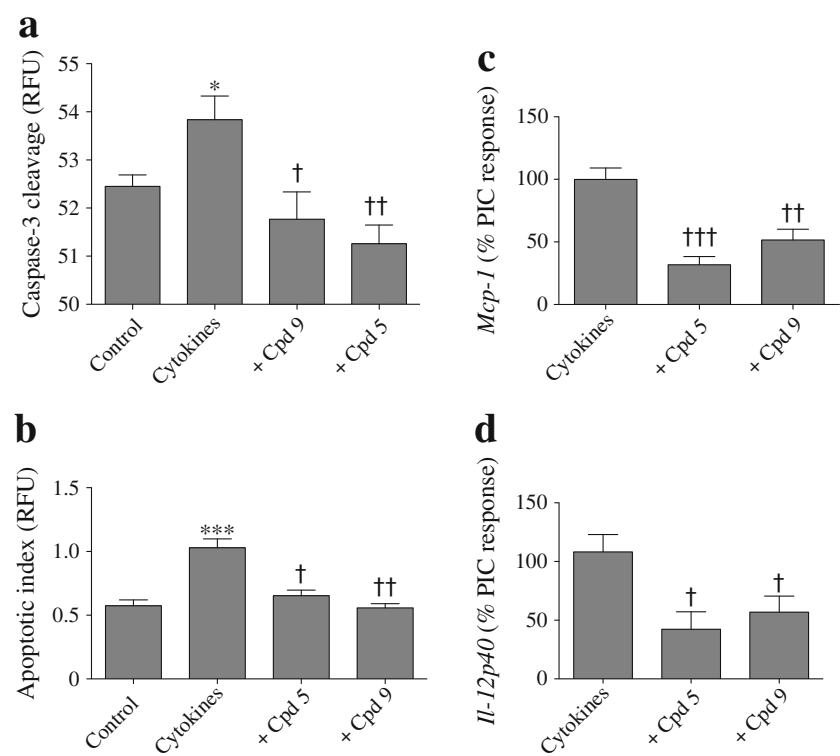

Fig. 4 Preserved GSIS and cell survival in primary mouse islets exposed to inflammatory cytokines. Cytokine-induced apoptosis in islets from B16 mice measured by caspase-3 activation (a) and quantitative microscopic analysis (b) and induced gene expression for Mcpl (c) or Il-12p40 (d) in the absence and presence of $10 \mu \mathrm{mol} / 1$ Compound (Cpd) 5 or 9. PIC, proinflammatory cytokines. ${ }^{*} p<0.05$ and $* * * p<0.001$ relative to control; ${ }^{\dagger} p<0.05 ;{ }^{\dagger \dagger} p<0.01$ and ${ }^{\dagger \dagger} p<0.001$ relative to cytokines; $n \geq 3$ 
The fold induction of these genes relative to control (unstimulated and time-matched) islets is shown in Fig. 4c, d. The cytokine-mediated increases in gene expression were significantly reduced by co-culture with Compound 5 or $9(p<0.05)$. Islets from non-diabetic NOD mice were used to study the protective effect of Compound 9 against the effects of cytokines (ESM Fig. 5). Islets co-treated with Compound 9 were significantly protected from cytokine-induced apoptosis and upregulation of $M c p 1$ and $I l-12 p 40(p<0.05)$.

These data from primary mouse islets support the proposed role of 12-lipoxygenase in mediating islet cell death induced by inflammatory cytokines.

Inhibition of 12-lipoxygenase activity in vivo To determine whether systemic administration of Compound 5 reduced basal 12-S-HETE, mice were given the compound by intraperitoneal injection. Euglycaemic NOD mice were dosed daily for 3 days to assess compound tolerability. The dosing regimens were $30 \mathrm{mg} / \mathrm{kg}$ twice daily, $50 \mathrm{mg} / \mathrm{kg}$ twice daily or $50 \mathrm{mg} / \mathrm{kg}$ daily, with three or four mice per group. Mice were assessed using the Body Condition Score [32]. No significant adverse reactions were noted. Thirty minutes after the final injection blood was collected by cardiac puncture and the plasma was analysed for 12-S-HETE (Fig. 5a). Relative to vehicle control, a dose-related inhibition of plasma 12-S-HETE was observed in mice treated with Compound 5.

To explore the oral efficacy of Compound 5, male CD1 mice (three mice per time point) were administered a single bolus of $50 \mathrm{mg} / \mathrm{kg}$ Compound 5 by gavage. Plasma concentrations of the compound and the plasma level of 12-S-HETE were analysed at each time point post compound administration (Fig. 5b). The peak plasma concentration $(1,820 \mathrm{ng} / \mathrm{ml})$ of Compound 5 was reached at 30 min post administration and steady elimination occurred thereafter. The plasma half-life for $50 \mathrm{mg} / \mathrm{kg}$ Compound 5 given by the oral route was calculated to be $2.72 \mathrm{~h}$. The plasma level of 12-S-HETE was reduced over $60 \%$ by Compound 5, with peak inhibition occurring at $2 \mathrm{~h}$ post administration and levels returning towards pre-treatment levels thereafter. Reduction in plasma 12-S-HETE correlated with plasma compound exposure.

These data in mice support evidence of acute systemic efficacy for inhibition of 12-lipoxygenase activity by Compound 5 , identify a clear relationship between Compound 5 exposure and efficacy and indicate that the inhibition of 12lipoxygenase by Compound 5 is reversible.

Inhibition of 12-lipoxygenase preserves function and survival of human donor islets exposed to proinflammatory cytokines The ability of 12-lipoxygenase inhibitors to confer protection against damage associated with exposure to inflammatory cytokines was assessed in human donor islets. Stimulation of human islets with $\mathrm{AA} / \mathrm{IONO}$ elevated the levels of 12-S-HETE in culture media from a basal level of 2,482 \pm $204 \mathrm{ng} / \mathrm{ml}$ to a stimulated level of $6,460 \pm 249 \mathrm{ng} / \mathrm{ml}(p<0.01)$. Both of the 12-lipoxygenase inhibitors, Compound 5 and Compound 9, resulted in a concentration-dependent inhibition of AA/IONO-stimulated 12-S-HETE (Fig. 6a). Human islet dysfunction mediated by inflammatory cytokines was measured by GSIS following a $4 \mathrm{~h}$ cytokine exposure and by apoptosis following overnight cytokine exposure. Cytokinemediated uncoupling of GSIS (Fig. 6b) and induction of apoptosis (Fig. 6c) were significantly reduced by co-culture of human islets with the 12-lipoxygenase inhibitors $(p<0.05)$. Compounds alone did not affect the GSIS response (ESM Fig. 3c). Assessment of gene expression for $I L-12 p 40$ (Fig. 6d) and $I F N \gamma$ (Fig. 6e) was made across a minimum of six human donor islet preparations. Stimulation with the cytokine cocktail elevated $I L-12 p 40$ and $I F N \gamma$; this elevation was inhibited by co-treatment with Compound 5 or $9(p<0.05)$. No significant reduction in cytokineinduced gene expression of $I L-12 p 40$ or $I F N \gamma$ was observed with structural analogues that were not potent for inhibition of 12-lipoxygenase activity $\left(\mathrm{IC}_{50} \geq\right.$ $70 \mu \mathrm{mol} / 1$, data not shown).

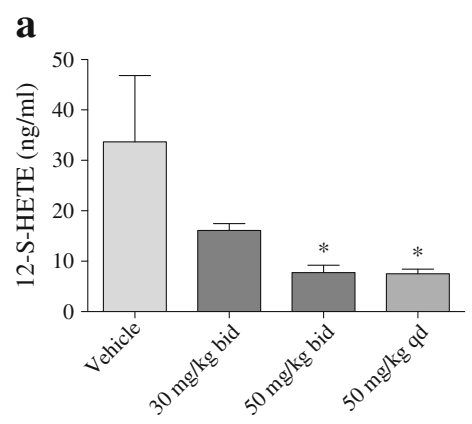

Fig. 5 Plasma 12-S-HETE in mice following systemic administration of Compound 5. (a) 12-S-HETE in mouse plasma was determined $30 \mathrm{~min}$ after a systemic intraperitoneal administration of vehicle or Compound 5 . Dosing frequency: bid, twice daily; qd, daily. (b) Compound 5 (Cpd 5)

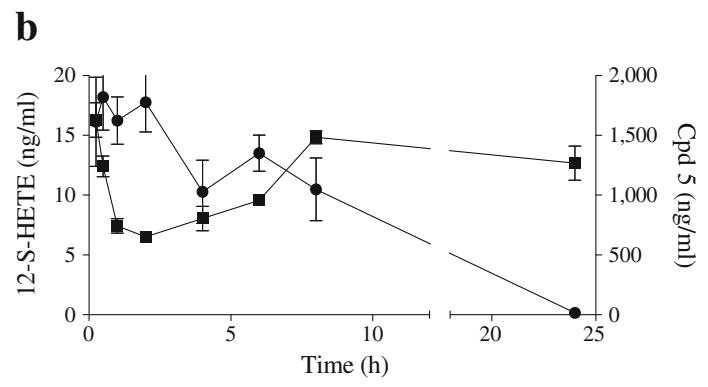

(circles) relative to plasma 12-S-HETE (squares) following oral bolus administration of $50 \mathrm{mg} / \mathrm{kg}$ Compound 5. Each data point plots the mean \pm SEM for $n \geq 3$ mice; ${ }^{*} p<0.05$ vs vehicle 

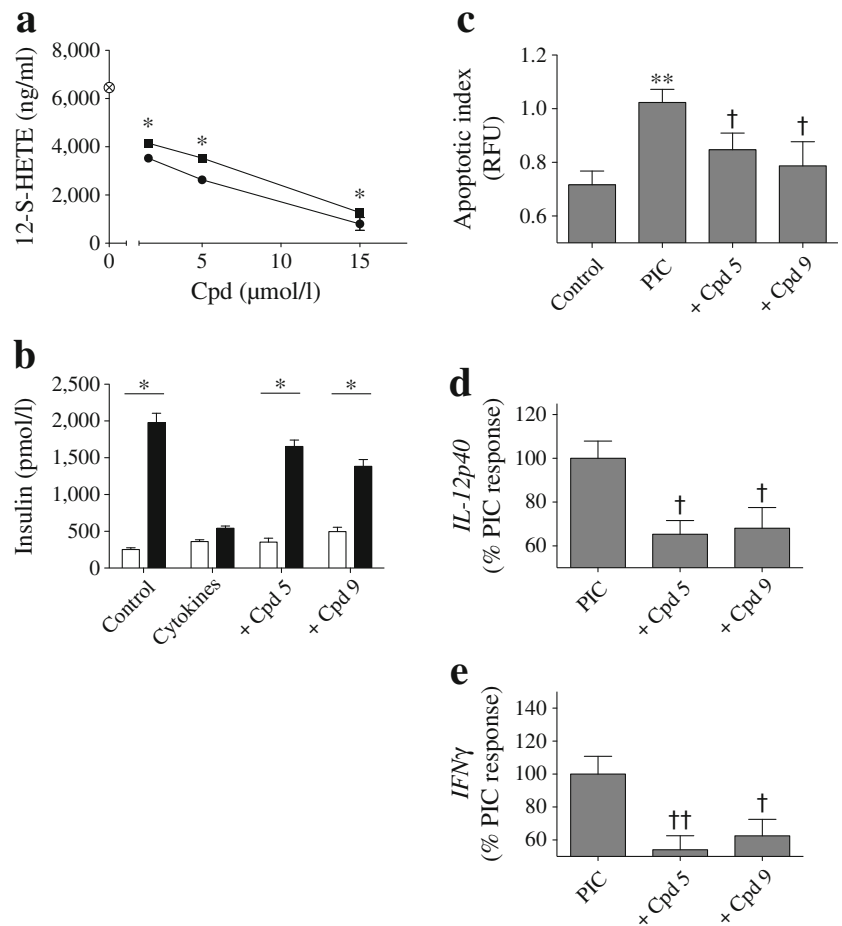

Fig. 6 Preserved GSIS and cell survival in primary human donor islets exposed to inflammatory cytokines. (a) AA/IONO stimulated 12-SHETE in human islets treated with Compound (Cpd) 5 (squares) or 9 (circles). Circled $\mathrm{X}$ on the $y$-axis shows $\mathrm{AA} / \mathrm{IONO}$ alone. (b) Insulin secretion in response to $3 \mathrm{mmol} / \mathrm{l}$ (white bars) or $16.7 \mathrm{mmol} / \mathrm{l}$ (black bars) glucose in untreated (Control) and cytokine-treated human islets in the absence or presence of $5 \mu \mathrm{mol} / 1$ of Compound (Cpd) 5 or 9 . (c-e) Quantified apoptosis (c) following treatment with cytokines in the absence or presence of $5 \mu \mathrm{mol} / \mathrm{l}$ Compound 5 or 9 and gene expression of $I L-12 p 40$ (d) or $I F N \gamma$ (e). PIC, proinflammatory cytokines. Data is from $\geq$ four donors $* p<0.05$ and $* * p<0.01$ for indicated comparison or relative to control; ${ }^{\dagger} p<0.05$ and ${ }^{\dagger \dagger} p<0.01$ relative to cytokines

The data acquired using human donor islets suggest that 12 lipoxygenase is a mediator of inflammatory cytokine-induced islet dysfunction. Selective inhibition of 12-lipoxygenase activity serves to preserve human islet function in vitro.

\section{Discussion}

Several lines of study accumulated over the last decades have identified a role for 12-lipoxygenase in disease pathophysiology. Review of 12-lipoxygenase and links to biological systems highlights the important role of 12-lipoxygenase in the development of type 1 diabetes [11, 15, 17, 23, 33, 34]. Studies of mouse models with transgenic deletion of 12 lipoxygenase suggest that activity of the 12-lipoxygenase enzyme strongly associates with beta cell dysfunction $[17$, $19,33]$. Islet-specific deletion of 12-lipoxygenase confers protection of islets from high fat, streptozotocin and cytokines [35].
These observations raise the possibility that selective inhibition of 12-lipoxygenase may find use as a therapeutic strategy for diabetes. Identifying a central role for 12-lipoxygenase in beta cell dysfunction has been limited by the lack of selective inhibitors. Previously purported inhibitors of 12 lipoxygenase (e.g. baicalein) have exhibited limited selectivity, being active against other lipoxygenase enzymes [36].

Following a high-throughput campaign, we reported a new series of first-in-class selective inhibitors of 12-lipoxygenase [28]. The identified 8-HQ series exhibited a greater than 100 fold selectivity for inhibition of 12-lipoxygenase relative to other lipoxygenases tested (5-lipoxygenase, 15-lipoxygenase) and COX1 and COX2 [28]. These compounds have made it possible to evaluate 12-lipoxygenase as a mediator of inflammatory cytokine-induced beta cell dysfunction.

Acute exposure of islets and beta cell lines to a threecytokine cocktail (TNF $\alpha$, IL-1 $\beta$, IFN $\gamma$ ) promotes beta cell dysfunction and elevated levels of islet apoptosis [13, 16, 27]. This cytokine cocktail induces expression of genes encoding for IL-12 and IFN $\gamma$ in islets and beta cells [27]. With relevance to clinical diabetes, inflammation is a recognised component of the development of both type 1 and type 2 diabetes [1-3]. Concomitant with beta cell dysfunction and decreased islet survival, inflammatory cytokine stimulation increased 12-lipoxygenase gene expression. These observations suggest that bioactive products resulting from elevated 12-lipoxygenase activity may connect inflammation and islet dysfunction. To determine whether 12-lipoxygenase is involved in the damaging effect of cytokines on human islets, human donor islets were treated with 12-S-HETE and read-outs attributed to inflammatory cytokine exposure were measured. 12-S-HETE is a stable bioactive lipid, produced as a result of 12-lipoxygenase activity. Consistent with the effects of inflammatory cytokines, direct acute stimulation of human donor islets with 12-S-HETE uncoupled GSIS, elevated islet apoptosis and induced the expression of genes encoding for IL-12 and IFN $\gamma$. These data, consistent with previous reports, indicate that 12-lipoxygenase is a mediator of inflammatory cytokine-induced islet/beta cell dysfunction [16].

Selective inhibition of 12-lipoxygenase offered the ability to explore the importance of 12-lipoxygenase activity in the mediation of inflammatory cytokine-induced beta cell dysfunction. Use of homogeneous beta cell lines additionally allowed exploration of the activity of 12-lipoxygenase in beta cells directly as opposed to its activity in other cells such as macrophages [23]. The 8-HQ compounds inhibited the stimulated 12-S-HETE production in mouse beta cell lines with $\mathrm{IC}_{50}$ values of $0.78-0.59 \mu \mathrm{mol} / \mathrm{l}$. Importantly, the 8 -HQ compounds blocked inflammatory cytokine-induced beta cell dysfunction as measured by static GSIS. The 8-HQ compounds similarly preserved islet function and survival in primary mouse or human donor islets exposed to inflammatory 
cytokines. Interestingly, the 8-HQ compounds inhibit cytokine induction of an IL-12/IFN $\gamma$ axis. Production and function of IL-12 in beta cells, as previously reported, suggest that IL-12 is associated with cytokine-mediated islet dysfunction [27]. Activity of 12-lipoxygenase has been described in other model systems as residing upstream of IL-12 [37].

Efficacy of 8-HQ compounds in human islets highlights the potential for 12-lipoxygenase inhibition to be translated to clinical studies. The 8-HQ compounds inhibit 12-S-HETE levels following systemic administration. This encouraging finding is further supported by a clear direct relationship between exposure and efficacy following oral administration. Initial pharmacokinetic studies indicate that the members of the 8-HQ compound class are bioavailable but have poor aqueous solubility. Medicinal chemistry optimisation of the 8-HQ class has proved challenging given that only modest improvements in potency are achieved. Less-than-desirable aqueous solubility has limited the development of parenteral formulations with which to perform long-term proof-of-concept studies in animal models of diabetes. This limitation is expected to be overcome in future studies following the recent identification of a new chemical class of selective 12-lipoxygenase inhibitors [38].

Collectively, these studies describe the efficacy of smallmolecular-weight compounds in the selective inhibition of 12lipoxygenase. The results provide concept validation for the use of 12-lipoxygenase inhibitors to confer islet protection. Preservation of beta cell function and survival is pertinent to the management of diabetes. Inflammation contributes to the initiation and progression of beta cell loss in both type 1 and type 2 diabetes. Clarification of the cellular mediators of cytokine-induced beta cell dysfunction and their selective inhibition are expected to offer new therapeutic strategies in diabetes that can be translated to the clinic to preserve functional beta cell mass.

\begin{abstract}
Acknowledgements Human donor islets were provided by the Integrated Islet Distribution Program (IIDP, http://iipd.coh.org/). W. Grzesik, Eastern Virginia Medical School, Norfolk, VA, USA, assisted with immunohistochemical studies.
\end{abstract}

Duality of interest The authors declare that there is no duality of interest associated with this manuscript.

Contribution statement DAT-F designed and directed the research, provided experimental data, interpreted data and wrote the article. JW, $\mathrm{LG}, \mathrm{AD}, \mathrm{NK}, \mathrm{GR}, \mathrm{AJ}$ and AS contributed to the acquisition and analysis of data and helped to review the article. TRH, JLN, DS and DJM contributed to the design and conception of the study, provided data interpretation and helped to review the article. All authors approved this version of the manuscript. DAT-F is the guarantor of this work.

Funding Support for this project was provided by the Juvenile Diabetes Research Foundation (JLN, TRH and DAT-F), the Intramural Research Program of the National Center for Advancing Translational Sciences and the Molecular Libraries Initiative of the National Institutes of Health Roadmap for Medical Research (U54MH084681) (GR, AJ, AS and DJM).

\section{References}

1. Donath MY (2014) Targeting inflammation in the treatment of type 2 diabetes: time to start. Nat Rev Drug Discov 13:465-476

2. Soleimanpour SA, Stoffers DA (2013) The pancreatic beta cell and type 1 diabetes: innocent bystander or active participant? Trends Endocrinol Metab 24:324-331

3. Westwell-Roper C, Ehses JA (2014) Is there a role for the adaptive immune system in pancreatic beta cell failure in type 2 diabetes? Diabetologia 57:447-450

4. Ehses JA, Perren A, Eppler E et al (2007) Increased number of isletassociated macrophages in type 2 diabetes. Diabetes 56:2356-2370

5. Eizirik DL, Sammeth M, Bouckenooghe T et al (2012) The human pancreatic islet transcriptome: expression of candidate genes for type 1 diabetes and the impact of pro-inflammatory cytokines. PLoS Genet 8:e1002552

6. Wellen KE, Hotamisligil GS (2005) Inflammation, stress, and diabetes. J Clin Invest 115:1111-1119

7. Tersey SA, Nishiki Y, Templin AT et al (2012) Islet beta-cell endoplasmic reticulum stress precedes the onset of type 1 diabetes in the nonobese diabetic mouse model. Diabetes 61:818-827

8. Arif S, Moore F, Marks K et al (2011) Peripheral and islet interleukin17 pathway activation characterizes human autoimmune diabetes and promotes cytokine-mediated beta-cell death. Diabetes 60:2112-2119

9. Atkinson MA, Eisenbarth GS, Michels AW (2014) Type 1 diabetes. Lancet 383:69-82

10. Baldwin AC, Green CD, Olson LK, Moxley MA, Corbett JA (2012) A role for aberrant protein palmitoylation in FFA-induced ER stress and beta-cell death. Am J Physiol Endocrinol Metab 302:E1390-E1398

11. Imai Y, Dobrian AD, Weaver JR et al (2013) Interaction between cytokines and inflammatory cells in islet dysfunction, insulin resistance and vascular disease. Diabetes Obes Metab 15(Suppl 3):117-129

12. Moran A, Bundy B, Becker DJ et al (2013) Interleukin-1 antagonism in type 1 diabetes of recent onset: two multicentre, randomised, double-blind, placebo-controlled trials. Lancet 381:1905-1915

13. Weaver JR, Holman TR, Imai Y et al (2012) Integration of proinflammatory cytokines, 12-lipoxygenase and NOX-1 in pancreatic islet beta cell dysfunction. Mol Cell Endocrinol 358:88-95

14. Brash AR (1999) Lipoxygenases: occurrence, functions, catalysis, and acquisition of substrate. J Biol Chem 274:23679-23682

15. Dobrian AD, Lieb DC, Cole BK, Taylor-Fishwick DA, Chakrabarti SK, Nadler JL (2011) Functional and pathological roles of the 12and 15-lipoxygenases. Prog Lipid Res 50:115-131

16. Ma K, Nunemaker CS, Wu R, Chakrabarti SK, Taylor-Fishwick DA, Nadler JL (2010) 12-Lipoxygenase products reduce insulin secretion and $\{$ beta $\}$-cell viability in human islets. J Clin Endocrinol Metab 95: 887-893

17. McDuffie M, Maybee NA, Keller SR et al (2008) Nonobese diabetic (NOD) mice congenic for a targeted deletion of 12/15-lipoxygenase are protected from autoimmune diabetes. Diabetes 57:199-208

18. Shannon VR, Ramanadham S, Turk J, Holtzman MJ (1992) Selective expression of an arachidonate 12-lipoxygenase by pancreatic islet beta-cells. Am J Physiol 263:E828-E836

19. Chen M, Yang ZD, Smith KM, Carter JD, Nadler JL (2005) Activation of 12-lipoxygenase in proinflammatory cytokinemediated beta cell toxicity. Diabetologia 48:486-495

20. Laybutt DR, Sharma A, Sgroi DC, Gaudet J, Bonner-Weir S, Weir GC (2002) Genetic regulation of metabolic pathways in beta-cells disrupted by hyperglycemia. J Biol Chem 277: 10912-10921

21. Ma Z, Ramanadham S, Corbett JA et al (1996) Interleukin-1 enhances pancreatic islet arachidonic acid 12-lipoxygenase product 
generation by increasing substrate availability through a nitric oxidedependent mechanism. J Biol Chem 271:1029-1042

22. Natarajan R, Gu JL, Rossi J et al (1993) Elevated glucose and angiotensin II increase 12-lipoxygenase activity and expression in porcine aortic smooth muscle cells. Proc Natl Acad Sci U S A 90:4947-4951

23. Green-Mitchell SM, Tersey SA, Cole BK et al (2013) Deletion of 12/ 15-lipoxygenase alters macrophage and islet function in NODAlox15(null) mice, leading to protection against type 1 diabetes development. PLoS One 8:e56763

24. Nunemaker CS, Chen M, Pei H et al (2008) 12-Lipoxygenaseknockout mice are resistant to inflammatory effects of obesity induced by Western diet. Am J Physiol Endocrinol Metab 295:E1065-E1075

25. Sears DD, Miles PD, Chapman J et al (2009) 12/15-Lipoxygenase is required for the early onset of high fat diet-induced adipose tissue inflammation and insulin resistance in mice. PLoS One 4:e7250

26. Cole BK, Morris MA, Grzesik WJ, Leone KA, Nadler JL (2012) Adipose tissue-specific deletion of 12/15-lipoxygenase protects mice from the consequences of a high-fat diet. Mediat Inflamm 2012:851798

27. Taylor-Fishwick DA, Weaver JR, Grzesik W et al (2013) Production and function of IL-12 in islets and beta cells. Diabetologia 56:126-135

28. Kenyon V, Rai G, Jadhav A et al (2011) Discovery of potent and selective inhibitors of human platelet-type 12- lipoxygenase. J Med Chem 54:5485-5497

29. Carter JD, Dula SB, Corbin KL, Wu R, Nunemaker CS (2009) A practical guide to rodent islet isolation and assessment. Biol Proced Online 11:3-31

30. Cozar-Castellano I, Harb G, Selk K et al (2008) Lessons from the first comprehensive molecular characterization of cell cycle control in rodent insulinoma cell lines. Diabetes 57: 3056-3068

31. Weaver JR, Taylor-Fishwick DA (2013) Regulation of NOX-1 expression in beta cells: a positive feedback loop involving the Srckinase signaling pathway. Mol Cell Endocrinol 369:35-41

32. Ullman-Cullere MH, Foltz CJ (1999) Body condition scoring: a rapid and accurate method for assessing health status in mice. Lab Anim Sci 49:319-323

33. Bleich D, Chen S, Zipser B, Sun D, Funk CD, Nadler JL (1999) Resistance to type 1 diabetes induction in 12-lipoxygenase knockout mice. J Clin Invest 103:1431-1436

34. Imai Y, Morris MA, Dobrian AD, Taylor-Fishwick DA, Nadler JL (2013) Inflammatory pathways linked to beta cell demise in diabetes. In: Islam S (ed) The islets of Langerhans, 2nd edn. Springer, Dordrecht

35. Tersey SA, Maier B, Nishiki Y, Maganti AV, Nadler JL, Mirmira RG (2014) 12-Lipoxygenase promotes obesity-induced oxidative stress in pancreatic islets. Mol Cell Biol 34:3735-3745

36. Deschamps JD, Kenyon VA, Holman TR (2006) Baicalein is a potent in vitro inhibitor against both reticulocyte 15-human and platelet 12-human lipoxygenases. Bioorg Med Chem 14: 4295-4301

37. Zhao L, Cuff CA, Moss E et al (2002) Selective interleukin-12 synthesis defect in 12/15-lipoxygenase-deficient macrophages associated with reduced atherosclerosis in a mouse model of familial hypercholesterolemia. J Biol Chem 277:35350-35356

38. Luci DK, Jameson JB 2nd, Yasgar A et al (2014) Synthesis and structure-activity relationship studies of 4-((2-hydroxy-3methoxybenzyl)amino)benzenesulfonamide derivatives as potent and selective inhibitors of 12-lipoxygenase. J Med Chem 57:495-506 